\title{
Angewandte
}

Supporting Information

(C) Wiley-VCH 2010

69451 Weinheim, Germany

\section{Analysis of Short Tandem Repeats by using SERS Monitoring and Electrochemical Melting**}

Damion K. Corrigan, Nittaya Gale, Tom Brown, and Philip N. Bartlett*

anie_201001389_sm_miscellaneous_information.pdf 


\section{List of Supporting Information}

\section{Experimental Section}

2. Figure S1. D16S539 - 10 Repeats. Potential scanned at $-0.5 \mathrm{mV} \mathrm{s}^{-1}$ and spectra recorded at $25 \mathrm{mV}$ intervals between -0.550 and $-1.150 \mathrm{~V}$.

3. Figure S2. D16S539 - 11 Repeats. Potential scanned at $-0.5 \mathrm{mV} \mathrm{s}^{-1}$ and spectra recorded at $25 \mathrm{mV}$ intervals between -0.550 and $-1.150 \mathrm{~V}$.

4. Figure S3. D16S539 - 12 Repeats. Potential scanned at $-0.5 \mathrm{mV} \mathrm{s}^{-1}$ and spectra recorded at $25 \mathrm{mV}$ intervals between -0.550 and $-1.150 \mathrm{~V}$.

5. Figure S4. D16S539 - 13 Repeats. Potential scanned at $-0.5 \mathrm{mV} \mathrm{s}^{-1}$ and spectra recorded at $25 \mathrm{mV}$ intervals between -0.550 and $-1.150 \mathrm{~V}$.

6. Figure S5. D16S539 - 14 Repeats. Potential scanned at $-0.5 \mathrm{mV} \mathrm{s}^{-1}$ and spectra recorded at $25 \mathrm{mV}$ intervals between -0.550 and $-1.150 \mathrm{~V}$.

7. Figure S6. Replicate melting curves for polymorphs 10 and 11 of D16S530. Points represent mean values and bars S.D. $n=3$.

\section{Multiplex Measurements}

9. $\quad$ Figure S7. Multiplex SERS spectra for DYS19 - 13R (Cy3) and D16S539 11R (Texas Red) recorded at different potentials.

10. Figure S8. Multiplex SERS spectra for DYS19 - 13R (Cy3) and D16S539 12R (Texas Red) recorded at different potentials.

11. Figure S9. Melting Curves for DYS19 - 13R (Cy3 peak at $1585 \mathrm{~cm}^{-1}$ ) and D16S539-11 and 12R (Texas Red peak at $1501 \mathrm{~cm}^{-1}$ ) using data taken from Figures S7 and S8. 


\section{Experimental Section}

\section{SSV preparation}

Glass microscope slides were coated with a $10 \mathrm{~nm}$ chromium adhesion layer followed by a $200 \mathrm{~nm}$ layer of gold using a standard thermal evaporation. After deposition the slides were cut into pieces $(2 \times 1.5 \mathrm{~cm})$ and cleaned for $90 \mathrm{~min}$ by sonication in isopropyl alcohol. After cleaning, the pieces were washed in deionised water and then submerged in $10 \mathrm{mM}$ cystamine in ethanol for $72 \mathrm{~h}$. Upon removal from cystamine solution, the gold pieces were again washed in deionised water before assembly of $600 \mathrm{~nm}$ polystyrene spheres (Duke Scientific). Spheres were arranged by cutting out and discarding a trapezium shaped area from a $2 \times 1.5 \mathrm{~cm}$ area of parafilm, placing the film onto the prepared gold surface, covering with a glass cover slip and heating at $60{ }^{\circ} \mathrm{C}$ on a hot plate to seal. The $600 \mathrm{~nm}$ sphere solution was then introduced into the arrangement so it was in contact with the gold surface; the arrangement was then placed at an angle of $15^{\circ}$ for $24 \mathrm{~h}$ at $15^{\circ} \mathrm{C}^{[10]}$. The closely packed monolayer of $600 \mathrm{~nm}$ polystyrene spheres obtained after removal of the glass and parafilm served as a template for the subsequent electrodeposition of gold. Electrodeposition of gold was carried out using $19.9 \mathrm{ml}$ of commercial gold electroplating solution (ECF 60, Technic Inc) to which $0.1 \mathrm{ml}$ of an additive (Brightener E3, Technic Inc) had been added to produce a suitable finish. Masking of the gold surface was carried out using varnish, the area intended for gold electrodeposition was left unmasked and in an electroplating bath was submerged beneath the surface of the electroplating solution. Electrodeposition was carried out under potentiostatic control at $-0.72 \mathrm{~V}$ vs a homemade saturated calomel electrode (SCE) and using a platinum mesh counter electrode. Deposition was terminated when the amount of charge necessary to deposit the gold to a height of $0.8 D(480 \mathrm{~nm})$ had been passed. The SSV substrate was then sonicated in $N, N$-dimethylformamide for $1 \mathrm{~h}$ in order to dissolve the polystyrene spheres.

\section{PCR Amplification}

PCR was carried out using $20 \mathrm{ng}$ of target sequence (table 1) present in a reaction volume of $20 \mu \mathrm{l}$. The reaction volume contained $0.5 \mu \mathrm{M}$ Texas Red labelled forward primer, and $0.05 \mu \mathrm{M}$ reverse primer, $0.5 \mathrm{mM} \mathrm{dNTPs}$ (Qiagen, Crawley, UK), 1 x Qiagen PCR Buffer (Qiagen, Crawley, UK), $3 \mathrm{mM} \mathrm{MgCl}$ and 1 unit of hot start DNA polymerase (Qiagen, Crawley, UK). PCR reactions were performed using a thermocycler and by employing an activation step of $95^{\circ} \mathrm{C}$ for $15 \mathrm{~min}$, followed by 35 cycles of $95^{\circ} \mathrm{C}(20 \mathrm{~s}), 55^{\circ} \mathrm{C}(30 \mathrm{~s})$, and $72{ }^{\circ} \mathrm{C}(30 \mathrm{~s})$.

\section{Probe immobilization and DNA Hybridisation}

The thiol modified probe sequence was diluted to a concentration of $1 \mathrm{uM}$ in $\mathrm{pH} 7.010 \mathrm{mM}$ Tris $1 \mathrm{M} \mathrm{NaCl}$ buffer. The SSV substrate was exposed to probe solution for $48 \mathrm{hrs}$ at $4{ }^{\circ} \mathrm{C}$ followed by exposure to $10 \mu \mathrm{M} 6$ Mercaptohexanol in $\mathrm{pH} 7.0,10 \mathrm{mM}$ Tris $1 \mathrm{M} \mathrm{NaCl}$ buffer for $30 \mathrm{~min}$ at $4{ }^{\circ} \mathrm{C}$. The Texas Red labelled PCR product was then added to $250 \mu \mathrm{l}$ of $\mathrm{pH} 7.0,10 \mathrm{mM}$ Tris $100 \mathrm{mM} \mathrm{NaCl}$ buffer and allowed to hybridise with capture probe at $4{ }^{\circ} \mathrm{C}$ for $30 \mathrm{~min}$.

\section{Electrochemical Melting.}

Electrochemical melting experiments were performed in a custom built cell (Ventacon, Winchester, UK). The SSV chip was connected into the cell before introducing $\mathrm{pH} 7.0,10 \mathrm{mM}$ Tris $10 \mathrm{mM} \mathrm{NaCl}$ measurement buffer into the cell. A $25 \mathrm{~mm}$ diameter circular glass cover slip was placed on top of the SSV and the cell lid screwed down prior to secure attachment to the microscope stage. The cell was connected to an EcoChemie micro Autolab III potentiostat/galvanostat. A series of potentials from $-0.3 \mathrm{~V}$ to $-1.5 \mathrm{~V}$ was applied. Potential steps of $-100 \mathrm{mV}$ were applied every $300 \mathrm{~s}$ with SERS spectra being recorded approximately $290 \mathrm{~s}$ after application of the potential step. Experiments were performed where a linear sweep of potential was applied using a scan rate of $0.5 \mathrm{mV} \mathrm{s}^{-1}$ starting from $-0.4 \mathrm{~V}$ and reaching $-1.7 \mathrm{~V}$ or less. SERS spectra were recorded every $25 \mathrm{mV}$. Experiments were carried out at room temperature.

\section{Raman Instrumentation and Data Analysis}

Spectra were acquired using a UL-WD 50x objective on a Renishaw 2000 Raman microscope. A $632.8 \mathrm{~nm} \mathrm{He}-\mathrm{Ne}$ laser was employed with a laser spot diameter of $1 \mu \mathrm{m}$. Spectra were recorded for $5-10 \mathrm{~s}$ in a static mode centered at $1450 \mathrm{~cm}^{-1}$ with a laser power of $2.4 \mathrm{~mW}$.

For calculation of peak heights, a background subtraction was carried out using a manual baseline function within Origin 7.0 (OriginLab, Northampton, MA). A Boltzmann function was fitted to melting curves using Origin 7.0. 
Oligonucleotide and Texas Red labelled oligonucleotide sequences (see table 1) were purchased from ATDBio (Southampton, UK). Millipore water $18.3 \mathrm{M} \Omega \mathrm{cm}$ was employed throughout the study. Ethanol, $N, N$ dimethylmethanamide and isopropyl alcohol were purchased from Fisher Scientific (Loughborough, UK). Cystamine was purchased from Sigma (Poole, Dorset, UK).

\section{SERS spectra recorded from D16S539 polymorphs 10 - 14 during a sweep of potential $\left(0.5 \mathrm{mV} \mathrm{s}^{-1}\right)$}

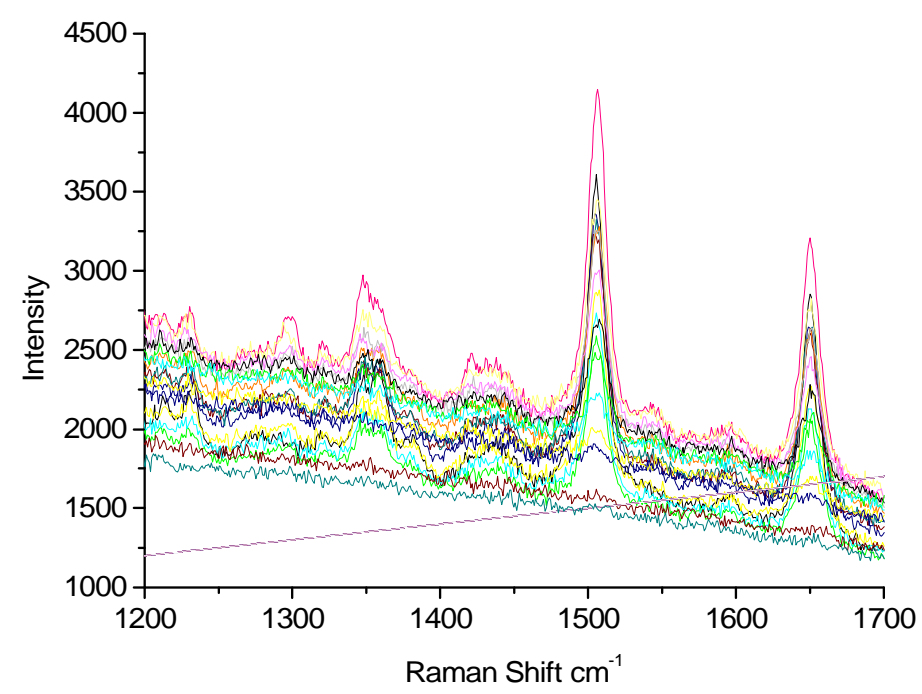

Figure S1. D16S539 - 10 Repeats. Potential scanned at $-0.5 \mathrm{mV} \mathrm{s}^{-1}$ and spectra recorded at $25 \mathrm{mV}$ intervals between -0.550 and $-1.150 \mathrm{~V}$.

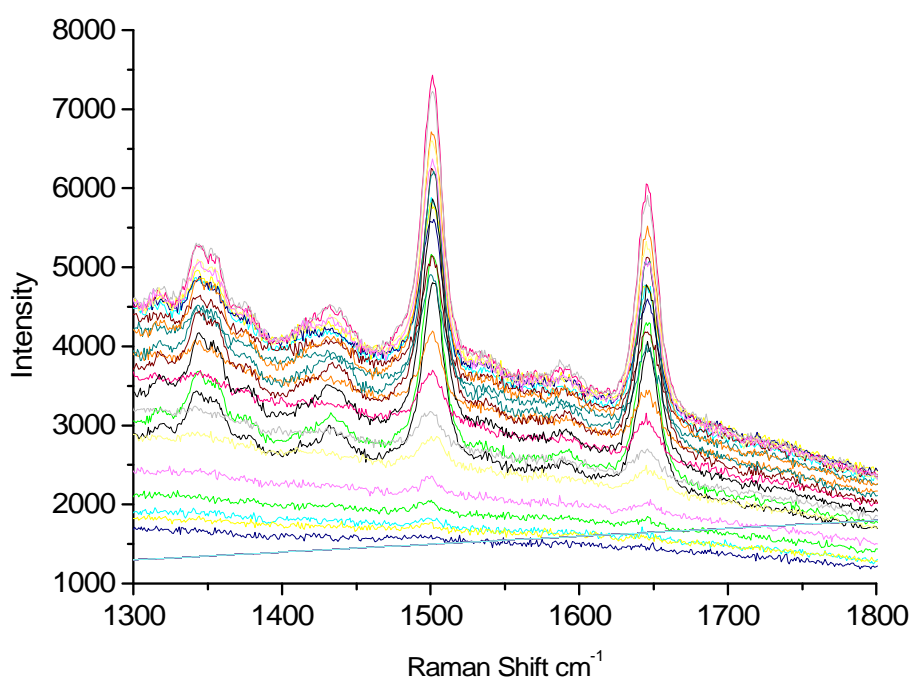

Figure S2. D16S539 - 11 Repeats. Potential scanned at $-0.5 \mathrm{mV} \mathrm{s}^{-1}$ and spectra recorded at $25 \mathrm{mV}$ intervals between -0.600 and $-1.300 \mathrm{~V}$. 


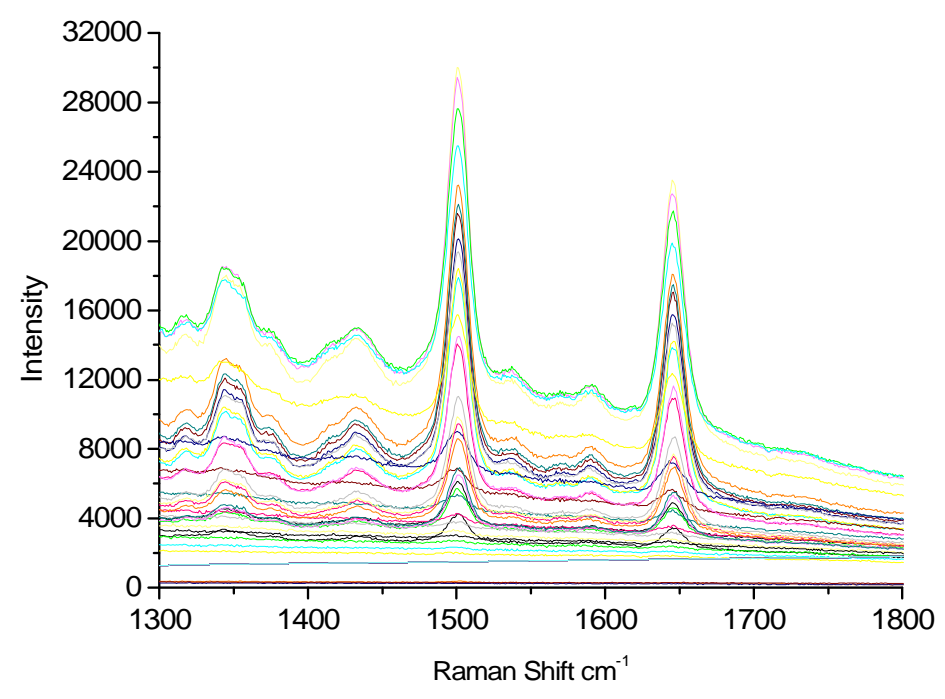

Figure S3. D16S539 - 12 Repeats. Potential scanned at $-0.5 \mathrm{mV} \mathrm{s}^{-1}$ and spectra recorded at $25 \mathrm{mV}$ intervals between -0.600 and $-1.525 \mathrm{~V}$.

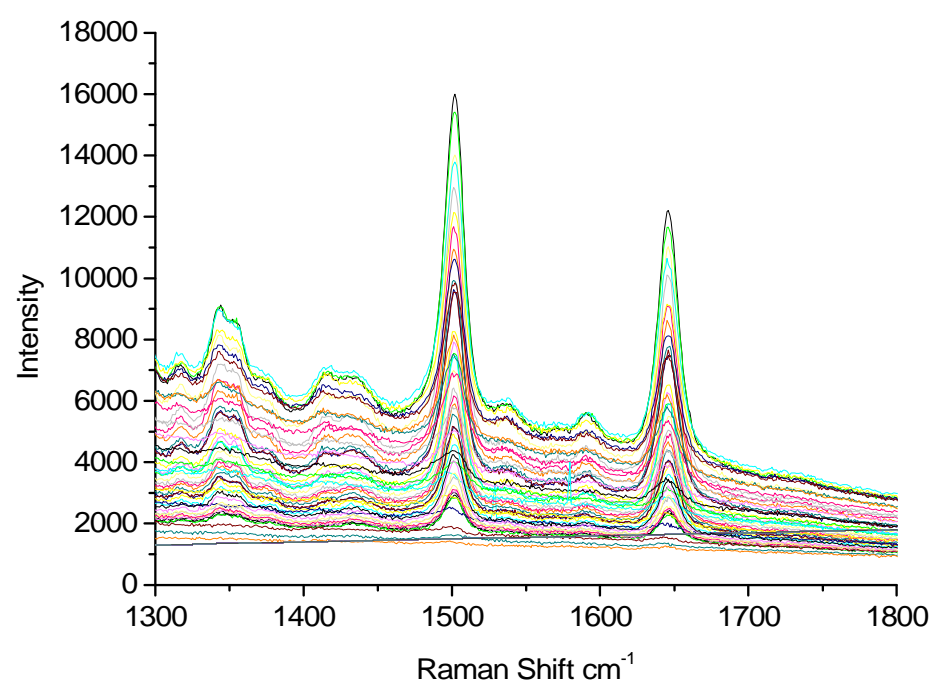

Figure S4. D16S539 - 13 Repeats. Potential scanned at $-0.5 \mathrm{mV} \mathrm{s}^{-1}$ and spectra recorded at $25 \mathrm{mV}$ intervals between -0.600 and $-1.700 \mathrm{~V}$. 


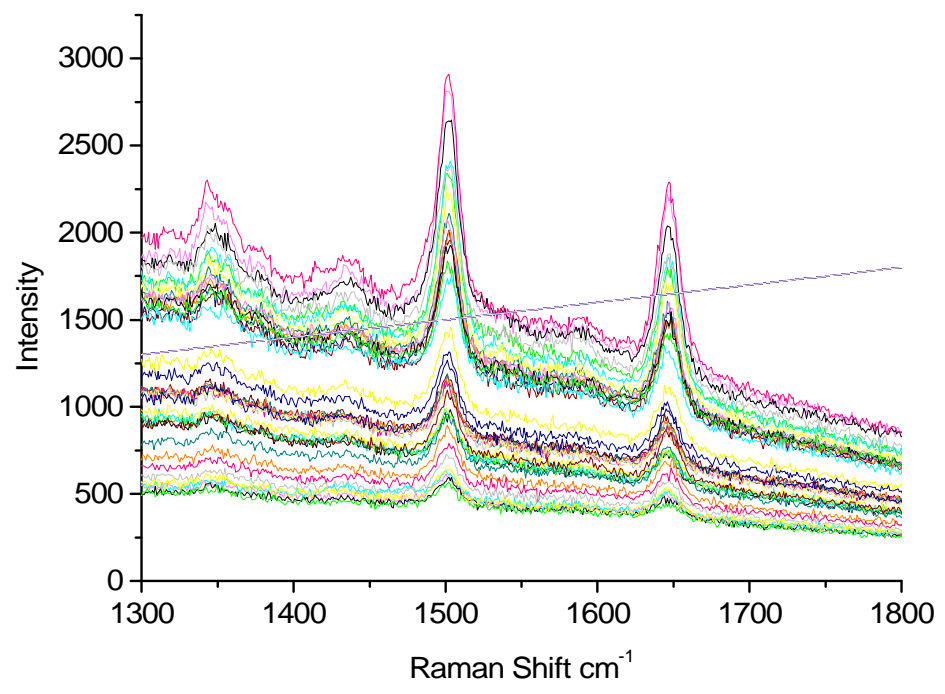

Figure S5. D16S539 - 14 Repeats. Potential scanned at $-0.5 \mathrm{mV} \mathrm{s}^{-1}$ and spectra recorded at $25 \mathrm{mV}$ intervals between -0.800 and $-1.800 \mathrm{~V}$.

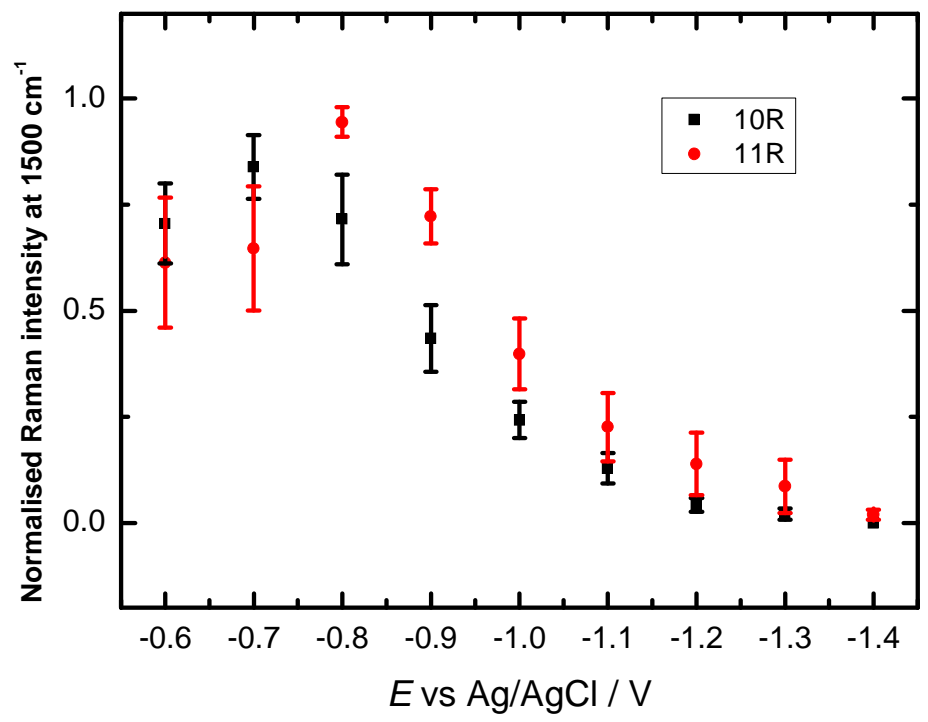

Figure S6. Replicate melting curves for polymorphs 10 and 11 of D16S530. Points represent mean values and bars standard deviations $(n=3)$. 


\section{Multiplex Measurements}

\section{Electrochemical Melting Experiments with 2 STRs}

Electrochemical melting experiments were conducted as described above, using $10 \mathrm{mM}$ Tris Buffer $+10 \mathrm{mM}$ $\mathrm{NaCl}$ and $-100 \mathrm{mV}$ potential steps over the range $-0.3 \mathrm{~V}$ to $-1.5 \mathrm{~V}$ vs $\mathrm{Ag} / \mathrm{AgCl}$. Raman instrumentation, cell setup, laser power and data acquisition were as described above.

Capture probe, template and primer sequences for DYS19

\begin{tabular}{|c|c|}
\hline & Sequence \\
\hline Capture Probe & $(\mathrm{TCTA})_{15} \mathrm{CCTA}(\mathrm{TCTA})_{3}$ AAACAC-H-XXX \\
\hline Template & $\begin{array}{l}\text { GTGTTTTAGATAGATAGATAGGTAGATAGATAGATAGATAGATAGATAGATAGATAGAT } \\
\text { AGATAGATAGATAGATAGATAGATATAGTGACACTCTCCTT }\end{array}$ \\
\hline Forward Primer & Cy3 - GTGTTTTAGATAGATAGATAGG \\
\hline Reverse Primer & AAGGAGAGTGTCACTATATC \\
\hline
\end{tabular}

$\mathrm{X}=$ dithiol monomer; $\mathrm{H}=$ hexaethylene glycol spacer

\section{Dual immobilisation and preparation of SSVs for experimentation}

Gold SSV substrates were prepared as described above using $600 \mathrm{~nm}$ diameter polystyrene spheres. Capture probes for D16S539 and DYS19 were diluted to a concentration of $0.05 \mu \mathrm{M}$ each in pH $7.010 \mathrm{mM}$ Tris Buffer +1 $\mathrm{M} \mathrm{NaCl}$. SSVs were submerged in the immobilisation solution for $48 \mathrm{~h}$. After immobilisation SSVs were rinsed in deionised water. Blocking was then carried out by submerging the SSVs in $10 \mu \mathrm{M} 6$-mercaptohexanol for $1 \mathrm{~h}$. A hybridisation solution was prepared by diluting $20 \mu \mathrm{L}$ of D16S539 and $20 \mu \mathrm{L}$ of DYS19 PCR in $460 \mu \mathrm{L}$ of 10 $\mathrm{mM}$ Tris Buffer $+100 \mathrm{mM} \mathrm{NaCl}$. After blocking, the SSVs were rinsed in deionised water and subsequently incubated at $4{ }^{\circ} \mathrm{C}$ for $1 \mathrm{~h}$ in the hybridisation solution containing DYS19 and D16S539 PCR product. SERS measurements and electrochemical melting experiments were then conducted.

\section{Results}

Capture probes for D16S539 and DYS19 were co-immobilised on SSV substrates. The PCR product for D16S539 (labelled with Texas Red) and the PCR product for DYS19 (labelled with Cy3) were then co-hybridised on the substrate for $1 \mathrm{~h}$. SERS spectra were recorded and electrochemical melting experiments performed under the normal conditions. The signals for the two different Raman labels are clearly distinguishable (Figures S7 and S8) and can be separately analysed to derive the electrochemical melting curves (Figure S9). 


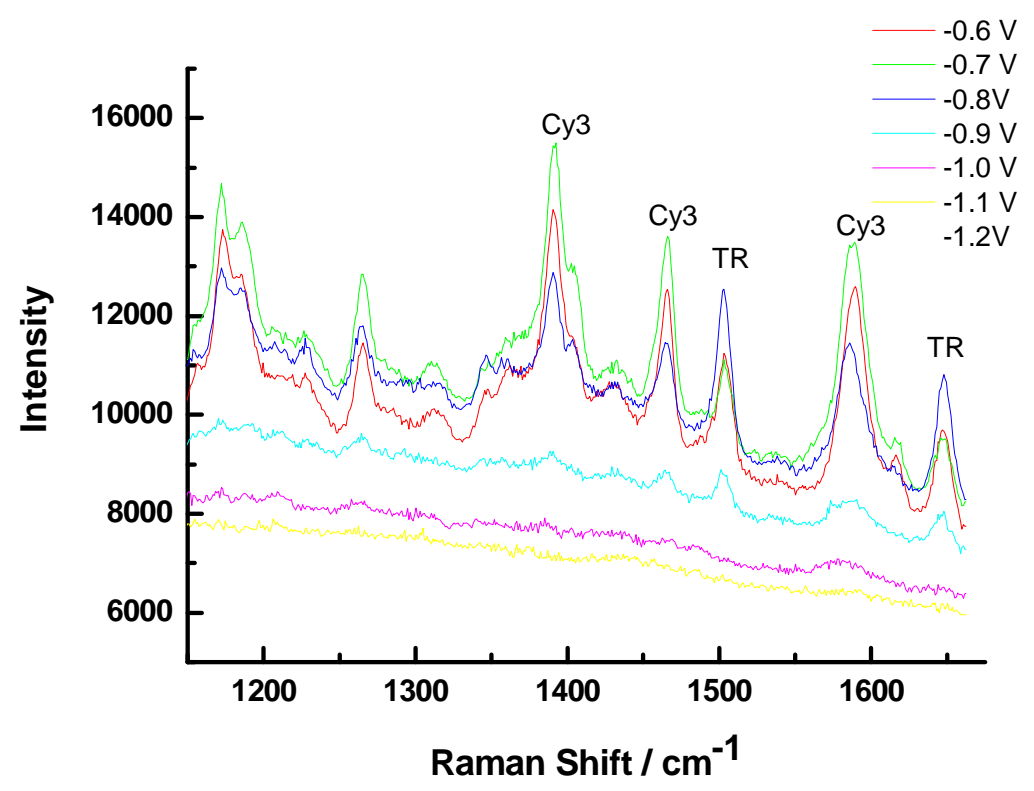

Figure S7. Multiplex SERS spectra for DYS19 - 13R (Cy3) and D16S539 11R (Texas Red) recorded at different potentials.

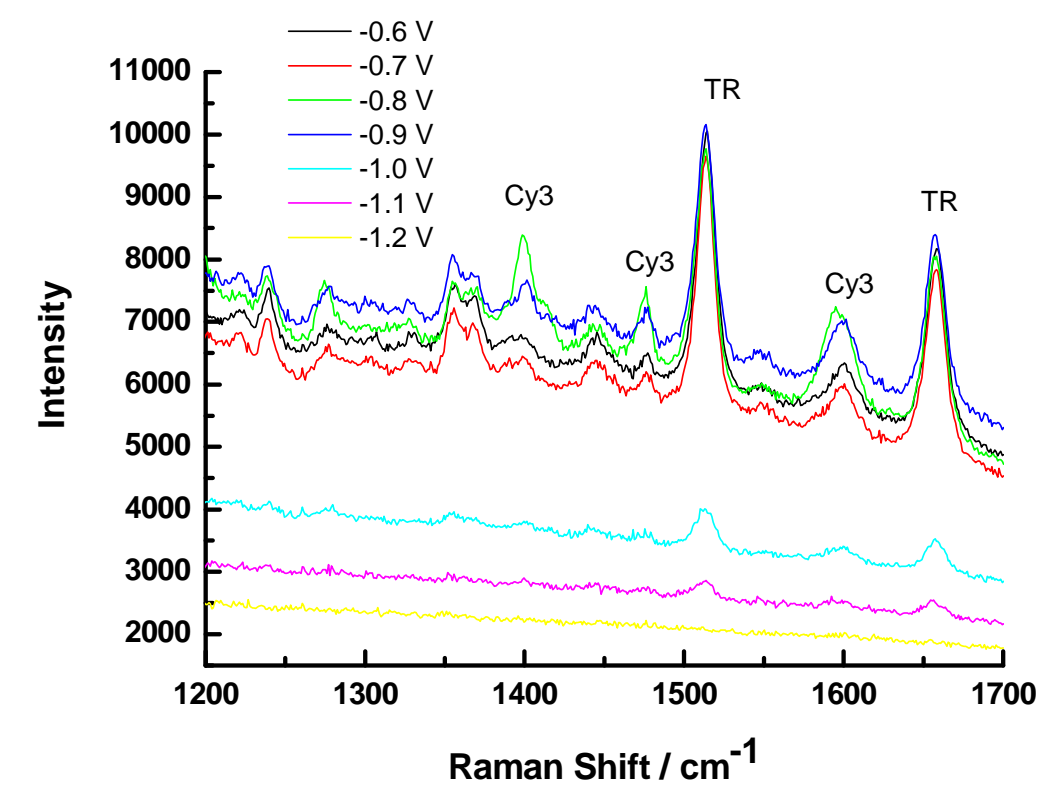

Figure S8. Multiplex SERS spectra for DYS19 - 13R (Cy3) and D16S539 12R (Texas Red) recorded at different potentials. 


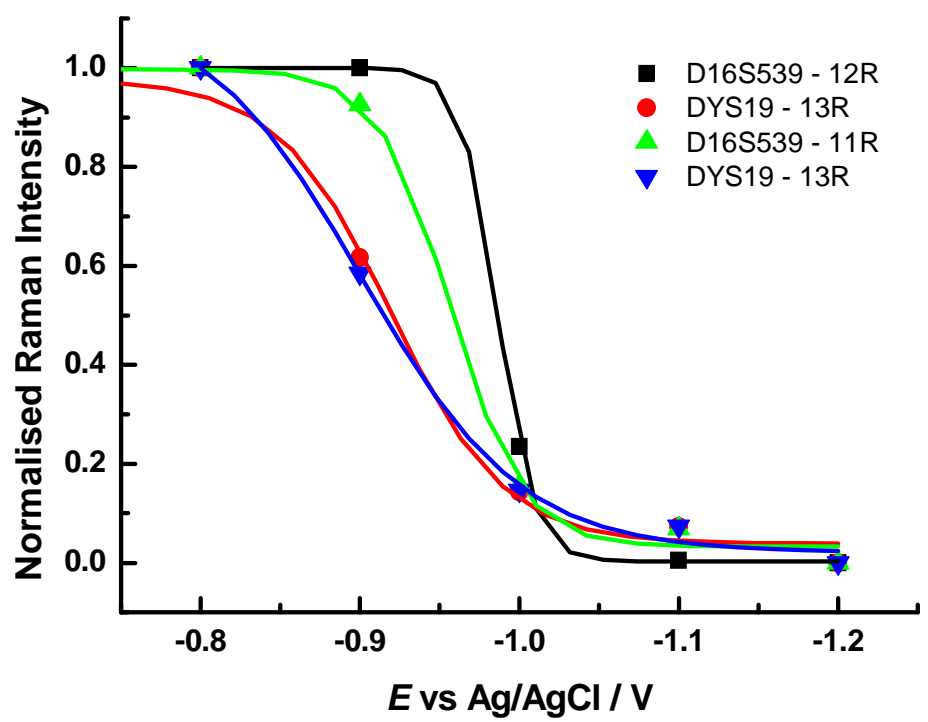

Figure S9. Melting Curves for DYS19 - 13R $\left(\mathrm{Cy} 3\right.$ peak at $\left.1585 \mathrm{~cm}^{-1}\right)$ and D16S539 - 11 and 12R (Texas Red peak at $1501 \mathrm{~cm}^{-1}$ ) using data taken from Figures S7 and S8. 